\title{
Percurso formativo de professores que ensinam Matemática em escolas indígenas do Acre
}

\author{
Formative training of teachers who teach Mathematics in indigenous communities of \\ Acre
}

\author{
Mara Rykelma da Costa Silva ${ }^{1}$ \\ Edcarlos Miranda de Souza ${ }^{2}$ \\ Itamar Miranda da Silva ${ }^{3}$
}

\begin{abstract}
Resumo
Frente à significância da educação escolar indígena no Acre, desenvolveu-se o presente trabalho que aborda os panoramas histórico, nacional e estadual, nos quais que se estabeleceu este modelo de ensino. Por meio de revisão bibliográfica, a qual considerou documentos como as Diretrizes Curriculares Nacionais para a Educação Escolar Indígena, objetivou-se a compreensão sobre o processo de solidificação de uma educação intercultural e diferenciada, apresentando reflexões que emergiram da experiência na participação do processo formativo de professores indígenas que ensinam matemática. Durante a experiência buscou-se respaldo na Antropologia, ampliando a compreensão quanto aos cuidados que o pesquisador/educador precisa tomar ao adotar práticas educacionais. Os resultados mostraram que trabalhar segundo o olhar do indígena, aproxima conteúdos matemático-acadêmicos ao cotidiano de comunidades, valorizando práticas culturais aliadas à compreensão da matemática como ciência.
\end{abstract}

Palavras-chave: Educação Escolar Indígena; Formação Docente; Educação Matemática; Interculturalidade.

\begin{abstract}
Faced with the significance of indigenous school education in Acre, the present work was developed to addresses the historical, national and local panorama in which this model of education was established. Through a bibliographic review, which considered documents such as the National Curriculum Guidelines for Indigenous School Education, a comprehension about the solidification's process of an intercultural and differentiated education was aimed, presenting reflections that emerged from the experience in the participation of an instructor training process of indigenous teachers who teach mathematics. During the experiment, support was sought in Anthropology, broadening the comprehension about cares that the researcher / educator needs to take when adopting educational practices. The results showed that working according to the native's approach brings academic mathematical contents to the daily life of the communities, valuing cultural practices allied to the comprehension of mathematics as science.
\end{abstract}

Keywords: Indigenous School Education; Teacher Training; Mathematical Education; Interculturality.

${ }^{1}$ Mestre em Matemática pela Universidade Federal do Acre. Professora do Instituto Federal de Educação, Ciência e Tecnologia do Acre, Brasil. Email: mararykelma@gmail.com

${ }^{2}$ Doutor em Estatística pela Universidade Federal de Lavras. Professor da Universidade Federal do Acre, Brasil. Email:profedcarlos@hotmail.com.

${ }^{3}$ Doutor em Educação Matemática pela Universidade Federal do Pará. Professor da Universidade Federal do Acre, Brasil. Email: itamar-miranda001@uol.com.br

Zetetiké, Campinas, SP, v.26, n.1, jan./abr. 2018, p.185-205

ISSN 2176-1744 
DOI: https://doi.org/ 10.20396/zet.v26i1.8650889

\section{Introdução}

A educação escolar indígena intercultural, diferenciada e bilíngue vem seguindo um modelo de ensino pautado no respeito à diversidade e à identidade de cada povo, modelo este que vai de encontro ao sistema educacional tradicional adotado no Brasil, desde a chegada dos portugueses, baseado no assimilacionismo sistematizado.

Nesse sentido, compreende-se que cada povo, grupo social ou comunidade possui características próprias, línguas, costumes, dialetos e ideias que são compartilhadas dentro de suas sociedades por meio de diferentes concepções, sistematizadas ou não.

No Acre, dados oficiais, divulgados em 2017 pelo periódico Acre em Números, apontam que atualmente vivem cerca de 19.962 indígenas, oriundos de 15 etnias distintas, cada uma com suas especificidades culturais, crenças, costumes e modos de ensinar. A Secretaria Estadual de Educação registrou, em 2015, 201 unidades de ensino localizadas em áreas indígenas, presentes em 12 municípios acreanos, com atuação de 648 professores, indígenas em sua maioria, atendendo a um público de aproximadamente 7.500 alunos.

Conhecidos alguns dos dados e admitido o fato de que professores indígenas compõem o sistema público de ensino do país, despertou-se o interesse em conhecer e divulgar o panorama da educação escolar indígena no estado do Acre, especificamente, no que se refere a profissionais que ensinam matemática, permitindo tecer considerações quanto à formação docente nessa área de ensino.

Reconhecendo que os povos indígenas, após travarem verdadeiras lutas para assegurar seus direitos, em particular, na conquista de seus territórios, bem como visando a compreensão acerca do surgimento da instituição escolar dentro de comunidades indígenas, é realizado um breve estudo exploratório sobre o processo de consolidação da educação indígena no país, paralelamente, a solidificação no Acre, o que permitiu a análise, segundo o panorama legal e evolutivo.

Dada a contribuição dos movimentos sociais em prol de direitos indígenas, realizouse, de modo sucinto, uma abordagem sobre a importância de algumas organizações sociais indígenas e indigenistas que introduziram pioneiramente ações voltadas para a educação escolar indígena, abrindo espaço para o ensino de matemática. Nesse sentido, o trabalho desenvolvido pelas instituições governamentais e não governamentais quanto à oferta de cursos de formação ou de capacitação profissional tornou-se um dos objetos deste estudo.

Para tanto, a revisão bibliográfica da presente pesquisa fundamenta-se na legislação vigente, com ênfase na Lei de Diretrizes e Base da Educação Nacional - LDB, o Referencial Curricular Nacional para Escolas Indígenas - RCNEI, as Diretrizes Curriculares Nacionais para a Educação Escolar Indígena e o Caderno n. ${ }^{\circ} 03$ da Secretaria de Educação Continuada, Alfabetização e Diversidade - SECAD, tais documentos permitiram a compreensão do processo de fortalecimento da educação indígena no país e dos diferentes significados a ela atribuídos. 
Além disso, estabeleceram-se considerações a partir da análise de dados extraídos de documentos, fornecidos pela Secretaria Estadual de Educação do Acre, sobre a educação escolar indígena no Acre, bem como de experiências vividas na condição de professora formadora exercida no XI Curso de Formação em Magistério Indígena, realizado em 2014, no município de Plácido de Castro, estado do Acre.

Dessa forma, o estudo visa discutir a formação do professor indígena, seu papel frente à busca pela consolidação de uma educação escolar específica e diferenciada, possibilitando a reflexão quanto ao significado atribuído a esses profissionais em suas comunidades, além da relevância e da necessidade da boa formação profissional, com ênfase na valorização do ensino de Matemática no seio de escolas indígenas, destacando práticas de ensino pautadas no respeito e valorização da cultura indígena.

\section{Consolidação de ambiente escolares em terras indígenas}

No Brasil, instituições escolares foram introduzidas em comunidades indígenas inesperadamente, por intermédio de ações desenvolvidas pelas missões jesuíticas a partir de 1500, com a chegada das primeiras expedições portuguesas ao território nacional, momento marcado pelo encontro de culturas distintas com consequente não aceitação do outro e a autovalorização cultural.

Para melhor compreensão desse processo de não aceitação, destaca-se a visão de Lévi-Strauss (2012), o qual afirma que a diversidade cultural raramente é vista pelos homens como um fenômeno natural. Incorrendo na recusa em reconhecer e aceitar essa diversidade, acabamos por repelir o outro, cujos costumes e conhecimentos passam a ser questionados e sobrepostos pelo majoritarismo.

Uma das primeiras experiências quanto à transmissão de conhecimentos com consequente sobreposição cultural, apontada pelo Ministério da Educação e divulgada pelos Cadernos da Secretaria de Educação Continuada, Alfabetização de Diversidade - SECAD, foi a missão jesuítica enviada de Portugal por D. João III, em 1549, cujos objetivos visavam converter nativos e torná-los submissos, levando à dizimação de milhares de índios.

No intuito de realizar a transmissão/sobreposição de conhecimentos como a leitura, a escrita e o sistema de contagem, bem como a doutrina cristã, os missionários percorriam aldeias em busca de crianças, consideradas menos intolerantes às mudanças, adotando como mecanismo de dominação o que D’Ambrósio (2011) trata como a exclusão do referencial cultural da classe ou do ser dominado.

O processo inicial de definição de doutrinas educacionais e de espaços para tal ocorre paralelo ao período colonial. A partir de 1845, através do Decreto $\mathrm{n}^{\circ} 426$, de 24 de julho daquele ano, a criação e a manutenção de ambientes educacionais para indígenas passou a ser regulamentada. 
No entanto, apesar da educação escolar indígena passar a contar com a delimitação de espaços, pode-se afirmar que os conhecimentos transmitidos nesses ambientes restringiam o ensino de matemática, já que as ações desenvolvidas priorizavam o ensino da língua portuguesa e a "civilização" de indígenas, segundo informações divulgadas pela SECAD.

Somente no início do século XX, com o surgimento de movimentos indigenistas no Brasil, o Estado sistematiza uma política educacional voltada para os interesses de comunidades indígenas, como resposta às pressões de órgãos governamentais e não governamentais, nacionais e internacionais, objetivando assistência e proteção de índios contra atos de exploração e de opressão, possivelmente uma forma de "compensação" a esses povos.

No Acre, cita-se algumas entidades indigenistas criadas a partir de movimentos sociais como a Comissão Pró Índio do Acre - CPI/AC, o Conselho Indigenista Missionário CIMI e o Conselho de Missões entre Índios - COMIN que, segundo Rêgo e Pereira (2010), teriam sido grandes protagonistas na consolidação de ações educacionais que respeitassem a diversidade cultural indígena.

Com efeito, sendo a educação escolar de indígenas considerada uma ação de proteção e assistência a eles, muitos órgãos indigenistas assumem o papel de integrar o índio à sociedade por intermédio da educação que, aos poucos, no intuito de dar autonomia aos índios, deixa de limitar os conteúdos ao ensino da leitura e da escrita e passa a considerar conhecimentos de outras áreas como a matemática.

Paralelo aos movimentos sociais em prol de indígenas, o crescimento econômico do país torna as terras indígenas alvo de interesse econômico, gerando conflitos e tornando latente a necessidade de diálogo entre indígenas e não indígenas.

No Acre, Cunha (2009) afirma que o início de tais conflitos deu-se em meados dos anos 90, com a instalação da frente extrativista da borracha, fenômeno que desencadeou o processo de ocupação das terras da Amazônia, tendo se deslocado para o Acre não apenas seringueiros nordestinos, mas também grandes latifundiários.

Esse processo migratório, com a consequente presença de famílias influentes na região, contribuiu para a implantação de escolas em seringais. Assim, a sistematização de conteúdos ganha significado e o ensino da matemática começa a ser formalmente ministrado em unidades educacionais.

Por fim, a consolidação da educação escolar indígena estabeleceu-se, motivada por esforços de indígenas e de não indígenas, amparada por uma legislação específica em resposta às pressões de movimentos, fortalecendo-se a partir do momento em que os povos indígenas passam a enxergá-la como instrumento de libertação da opressão e da aculturação imposta ao longo dos anos. 


\section{Regulamentação e Estruturação de escolas em terras indígenas no Acre}

A delimitação de ambientes educacionais em terras indígenas apenas começou a se estabelecer após o abandono da perspectiva integracionista e negadora, imposta aos indígenas durante séculos.

Como parte desse processo de abandono de perspectivas excludentes, pode-se mencionar a elaboração de documentos como a Carta das Nações Unidas, assinada em São Francisco, em 26 de junho de 1945, incorporada à legislação brasileira por meio do Decreto Presidencial $n^{\circ} 19.841$, de 22 de outubro do mesmo ano, que reforça a importância da educação frente à tentativa de promover a igualdade entre os homens e o respeito entre os povos.

No entanto, o documento de destaque nacional, quanto à assimilação de novas políticas indigenistas, formalmente inicia-se com a Constituição do Brasil de 1988, a qual reconhece a necessidade de uma escola diferenciada e assegura às comunidades indígenas, em seu Artigo 210, o uso de língua materna, bem como a adoção de processos próprios de aprendizagem que possam a garantir o desenvolvimento educacional e o respeito aos costumes e à cultura de cada povo.

Além da Carta Magna, no âmbito nacional, a Lei de Diretrizes e Bases da Educação Brasileira - LDB, Lei 9.394/96, enfatiza direitos garantidos como o da educação escolar diferenciada, intercultural e bilíngue, atribuindo à União a responsabilidade de apoiar tecnicamente e financeiramente esse sistema de ensino na busca de objetivos como:

I - Proporcionar aos índios, suas comunidades e povos, a recuperação de suas memórias históricas, a reafirmação de suas identidades étnicas e a valorização de suas línguas e ciências;

II - Garantir aos índios, suas comunidades e povos, o acesso às informações, conhecimentos técnicos e científicos da sociedade nacional e demais sociedades indígenas e não-índias. (Ministério da Educação e do Desporto, 1996, p.41 e 42).

A publicação do Decreto ${ }^{\circ}$ 6.861, de 27 de maio de 2009, também traz importantes contribuições, em seu Artigo $4^{\circ}$, parágrafo único, são dispostos elementos básicos para o estabelecimento de instituições escolares em comunidades indígenas, deixando claro que "A escola indígena será criada por iniciativa ou reivindicação da comunidade interessada, ou com sua anuência, respeitadas suas formas de representação".

Considerando a relevância do teor dos documentos, ora apresentados sobre o tema, de fato, o documento norteador para o estabelecimento dessa educação diferenciada é o Referencial Curricular Nacional para a Educação Indígena - RCNEI, de 1998, o qual embasa a construção de referenciais próprios, o direcionamento do funcionamento e do trabalho docente, além de auxiliar na elaboração e implantação de programas educacionais que atendam aos interesses de cada comunidade. 
A análise desses documentos regulamentadores permite afirmar que as instituições escolares em terras indígenas estabeleceram-se como um ambiente de afirmação da identidade própria.

Tendo assim se estabelecido, cabe ao professor a responsabilidade de gerir conhecimentos e intermediar ações no processo de ensino e aprendizagem. Documentos oficiais, como as Diretrizes Curriculares Nacionais para a Educação Escolar Indígena DCNEI, fazem menção à abrangência da função do professor, a saber:

\begin{abstract}
Os professores aparecem, em muitos casos, no cenário político e pedagógico como um dos principais interlocutores nos processos de construção do diálogo intercultural, mediando e articulando os interesses de suas comunidades com os da sociedade nacional em geral e com os de outros grupos particulares, promovendo a sistematização e organização de novos saberes e práticas. É deles também a tarefa de refletir criticamente e de buscar estratégias para promover a interação dos diversos tipos de conhecimentos que se apresentam e se entrelaçam no processo escolar: de um lado, os conhecimentos ditos universais, a que todo estudante, indígena ou não, deve ter acesso, e, de outro, os conhecimentos étnicos, próprios ao seu grupo social de origem, que, outrora negados, hoje assumem importância crescente nos contextos escolares indígenas. (DCNEI, 2012, p. 396).
\end{abstract}

No Acre, dados da Secretaria Estadual de Educação revelam que a Educação Escolar Indígena se estabeleceu solidamente a partir de 1999, após uma série de discussões visando a implantação de um programa próprio de Formação em Magistério Indígena que atendesse à demanda de formação e de capacitação profissional de professores que vinham atuando, ou que pudessem vir a atuar, no sistema de ensino.

Enfatiza-se que as primeiras ações educacionais, com foco na formação de professores indígenas no Acre, foram desenvolvidas por organizações não vinculadas ao Estado, como por exemplo a Comissão Pró Índio do Acre - CPI/ACRE, o Conselho de Missão entre Índios - COMIN e o Conselho Indigenista Missionário - CIMI, ações que acabaram por orientar políticas educacionais mais específicas, não apenas no estado.

Colares (2013), a partir de pesquisas com povos indígenas do Pará, afirma que em 1980 o Acre teria sido o primeiro estado brasileiro a ofertar um curso de formação específico para professores indígenas, organizado pela Comissão Pro-Índio - CPI/AC, em seguida, o estado do Amapá também teria iniciado um trabalho nesse sentido e, em 1990, em Rondônia, aconteceria o primeiro curso de capacitação para professores indígenas.

Atualmente, o estado, por meio do trabalho da Secretaria Estadual de Educação, possui uma Proposta Pedagógica diferenciada que destaca o diálogo de saberes e vem sendo executada pela equipe da Coordenação de Educação Indígena - CEI em parceria com outros órgãos, atendendo os territórios indígenas habitados pelas 15 etnias que compõem a população indígena do Acre.

Os mais de 240 povos indígenas brasileiros somam, segundo o Censo IBGE de 2010, o quantitativo de 896.917 pessoas em todo Brasil. No Acre, chegam ao número de 19.962. Destes, o Censo SEE/AC 2013 identificou aqueles matriculados na rede pública de 
DOI: https://doi.org/ 10.20396/zet.v26i1.8650889

ensino do estado, aproximadamente 7.500 alunos atendidos por 648 professores, indígenas em sua maioria.

A compreensão acerca da importância de processos formativos em capacitar profissionais oriundos da própria comunidade pode ser entendida, segundo o posicionamento de Gomes (2013) que, apesar de apresentar a visão antropológica, enfatiza que um ser integrante de um grupo social é mais apto a expressar sentimentos e valores presentes em discursos adotados por seu grupo do que um indivíduo alheio a esta comunidade.

Logo, pautando-se nesses princípios, mas seguindo a vertente educacional que valoriza o outro, acredita-se que é relevante promover a formação de professores indígenas para que eles próprios possam atuar em escolas indígenas.

Nessa perspectiva, a Secretaria Estadual de Educação do Acre, em parceria com a CPI/Acre, oferece, desde o ano 2000, cursos de formação e de capacitação de professores indígenas, baseados na Proposta Curricular de Magistério Indígena, logo, são discutidas questões sobre profissionais que ensinam matemática na educação básica da rede pública de ensino.

Considerando as informações da Tabela 1, podemos verificar a oferta dos cursos destinados aos professores indígenas no Acre:

Tabela 1 - Estrutura organizacional dos cursos de formação

\begin{tabular}{|c|c|c|c|}
\hline $\begin{array}{c}\text { Ano de } \\
\text { Realização }\end{array}$ & $\begin{array}{c}\text { Carga Horária } \\
\text { Geral }\end{array}$ & $\begin{array}{c}\mathbf{N}^{0} \text { de } \\
\text { Cursistas }\end{array}$ & Carga Horária por Temática \\
\hline \multirow{5}{*}{2000} & \multirow{5}{*}{311} & \multirow{5}{*}{75} & $\begin{array}{l}\text { Fundamentos de alfabetização e fundamentos de } \\
\text { EEI (44h) }\end{array}$ \\
\hline & & & Matemática $(\mathbf{8 8 h})$ \\
\hline & & & Linguística (56h) \\
\hline & & & Linguística (88h) \\
\hline & & & História (35h) \\
\hline \multirow{6}{*}{2001} & \multirow{6}{*}{301} & \multirow{6}{*}{73} & Língua Indígena (44h) \\
\hline & & & Língua Portuguesa (105h) \\
\hline & & & História (36h) \\
\hline & & & Matemática (44h) \\
\hline & & & Pedagogia (44h) \\
\hline & & & Geografia (28h) \\
\hline \multirow{5}{*}{2002} & \multirow{5}{*}{264} & \multirow{5}{*}{90} & Língua Indígena (44h) \\
\hline & & & Língua Portuguesa (44h) \\
\hline & & & Geografia (44h) \\
\hline & & & Matemática (66h) \\
\hline & & & Ciências (66h) \\
\hline \multirow{4}{*}{2003} & \multirow{4}{*}{264} & \multirow{4}{*}{96} & Língua Indígena (44h) \\
\hline & & & Artes e Educação Física (88h) \\
\hline & & & Português (88h) \\
\hline & & & Ciências (44h) \\
\hline \multirow{2}{*}{2004} & \multirow{2}{*}{264} & \multirow{2}{*}{151} & Legislação (44h) \\
\hline & & & Iniciação a Pesquisa (60h) \\
\hline
\end{tabular}


DOI: https://doi.org/ 10.20396/zet.v26i1.8650889

\begin{tabular}{|c|c|c|c|}
\hline & & & Matemática (40h) \\
\hline & & & Ciências (60h) \\
\hline & & & Fundamentos da Educação (60h) \\
\hline \multirow{6}{*}{2005} & \multirow{6}{*}{412} & \multirow{6}{*}{137} & Ciências (44h) \\
\hline & & & Fundamentos da Educação (88h) \\
\hline & & & História (44h) \\
\hline & & & Língua Indígena (88h) \\
\hline & & & Oficina Nixepupima (112h) \\
\hline & & & Oficina KeneYositi (36h) \\
\hline 2006 & 88 & 14 & Matemática (88h) \\
\hline \multirow{4}{*}{2006} & \multirow{4}{*}{264} & \multirow{4}{*}{164} & Ciências (44h) \\
\hline & & & Fundamentos da Educação (88h) \\
\hline & & & História (44h) \\
\hline & & & Língua Indígena (88h) \\
\hline \multirow{8}{*}{2008} & \multirow{8}{*}{396} & \multirow{8}{*}{249} & Língua Indígena (44h) \\
\hline & & & Iniciação à Pesquisa (44h) \\
\hline & & & História (44h) \\
\hline & & & Biologia (44h) \\
\hline & & & Química (44h) \\
\hline & & & Jogos e Recreações (44h) \\
\hline & & & Língua Portuguesa (44h) \\
\hline & & & $\begin{array}{l}\text { Atividade interdisciplinar: Geografia, } \\
\text { Matemática e Ciências Sociais (44h) }\end{array}$ \\
\hline \multirow{9}{*}{2010} & \multirow{9}{*}{391} & \multirow{9}{*}{220} & $\begin{array}{l}\text { Legislação e políticas públicas em Educação } \\
\text { Escolar Indígena (44h) }\end{array}$ \\
\hline & & & Língua Indígena (60h) \\
\hline & & & Fundamentos da Pesquisa (44h) \\
\hline & & & Educação Inclusiva (04h) \\
\hline & & & Saúde e Meio Ambiente (44h) \\
\hline & & & Química, Física e Matemática (60h) \\
\hline & & & Saúde e Meio Ambiente (27h) \\
\hline & & & Linguagem e Letramento (44h) \\
\hline & & & Metodologia de Alfabetização (64h) \\
\hline \multirow{3}{*}{2014} & \multirow{3}{*}{352} & \multirow{3}{*}{295} & Autonomia Indígena (92h) \\
\hline & & & Educação Matemática (130h) \\
\hline & & & Escola Indígena e sua história (130h) \\
\hline
\end{tabular}

Fonte: Secretaria Estadual de Educação do Acre, 2015

Sendo assim, podemos inferir que os dados apresentados na Tabela 1 elencam ações pedagógicas adotadas pela Secretaria de Educação do estado em parceria com a CPI/AC, quanto à promoção de cursos de formação diferenciada de professores indígenas, $\mathrm{o}$ quantitativo de profissionais em processo formativo, o ano de oferta e a carga horária destinada às áreas de conhecimento, sendo destacadas as ofertas do ensino de matemática.

Destaca-se que, das onze capacitações ofertadas nos moldes de Formação em Magistério, as ocorridas nos anos de 2003, 2005 e uma das promovidas em 2006, não tiveram o ensino de matemática incluído na proposta. No entanto, houve a oferta de um curso 
DOI: https://doi.org/ 10.20396/zet.v26il.8650889

específico sobre o ensino de matemática em 2006, mostrando o reconhecimento da importância e da necessidade do domínio da matemática para esses povos.

\section{Práticas culturais no processo formativo de professores indígenas que ensinam Matemática}

O presente estudo permite aferir que o início das discussões sobre práticas culturais no ensino de matemática no processo formativo de docentes indígenas baseado no XI Curso de Formação em Magistério Indígena, curso que ocorreu no período de 28 de julho a 12 de setembro de 2014, no município de Plácido de Castro, interior do estado do Acre, e trata-se, até o momento, do mais recente curso desta modalidade ofertado a professores indígenas que ensinam matemática em suas comunidades.

Durante o período destinado à Educação Matemática, foram contemplados aproximadamente 300 professores indígenas de diferentes etnias que atuam na educação escolar, oriundos de suas comunidades, com diferentes níveis de formação, denominados pela organização do evento, membros da Coordenação de Educação Indígena da SEE/AC, como professores cursistas. A distribuição dos cursistas pode ser observada na Tabela 2:

Tabela 2 - Estrutura organizacional segundo o nível de ensino/família linguística

\begin{tabular}{c|c|l|c}
\hline $\begin{array}{c}\text { Povo/Família } \\
\text { Linguística }\end{array}$ & Turma & \multicolumn{1}{|c}{ Formação/Escolarização } & $\begin{array}{c}\text { Número de } \\
\text { Professores }\end{array}$ \\
\hline \multirow{3}{*}{ HUNI KUI / PANO } & $\mathrm{A}$ & Ensino Fundamental Incompleto - até 5o Ano & 21 \\
\cline { 2 - 4 } & $\mathrm{B}$ & Ensino Fundamental Incompleto - até 9o Ano & 31 \\
\cline { 2 - 4 } & $\mathrm{C}$ & Ensino Fundamental Completo & 50 \\
\hline \multirow{2}{*}{$\begin{array}{c}\text { MANXINERI / } \\
\text { ARUAK }\end{array}$} & $\mathrm{E}$ & Ensino Médio Completo & 49 \\
\hline \multirow{2}{*}{$\begin{array}{c}\text { DIFERENTES } \\
\text { POVOS / PANO }\end{array}$} & $\mathrm{F}$ & Ensino Fundamental Incompleto & 39 \\
\cline { 2 - 4 } & $\mathrm{G}$ & Ensino Médio Incompleto & 36 \\
\cline { 2 - 4 } & $\mathrm{H}$ & Ensino Fundamental Incompleto & 20 \\
\hline
\end{tabular}

Fonte: Secretaria Estadual de Educação do Acre, 2015

Salientamos que o ensalamento, apresentado na Tabela 2, refere-se aos cursistas que participaram do Módulo de Educação Matemática, realizado no período de 04 a 21 de agosto de 2014, distribuídos de acordo com suas características linguísticas, costumes étnicos e o nível de escolaridade no intuito de estabelecer o respeito às diferenças e garantir aos formadores a abordagem de conteúdos relativamente homogênea.

Segundo o Relatório do XI Curso de Formação Magistério Indígena (2014), o curso teve seus conteúdos sistematizados em módulos: o primeiro, voltado para Autonomia Indígena, com carga horária de 92 horas; o segundo, direcionado à Educação Matemática, 
objeto de análises, com carga horária de 130 horas; e o último módulo, com abordagem sobre a Educação Escolar Indígena e sua História, também com 130 horas.

O processo formativo possibilitou o contato com aproximadamente 300 professores indígenas, tendo sido desenvolvido um trabalho formativo direto com a turma A, na condição de professor(a) formador(a), nomenclatura esta adotada no curso. A turma foi composta por 21 professores indígenas da etnia Huni Kuĩ, mais conhecidos como povo Kaxinawá, cujo nível de escolaridade restringia-se ao primeiro ciclo do Ensino Fundamental, mas que atuavam como professores em suas comunidades.

No módulo voltado à Educação Matemática, considerando principalmente o nível de escolarização da turma e as demandas dos profissionais, foram abordadas dentre outras temáticas, conteúdos relacionados ao Sistema Numérico Decimal, às Operações Fundamentais, ao Sistema de Medidas e à Educação Financeira, com ênfase na matemática que pode ser vivenciada no cotidiano indígena.

Para o desenvolvimento do percurso formativo, buscou-se respaldo em D'Ambrósio (2013), que defende a adoção de processos de ensino que respeitem as particularidades e especificidades de cada aluno, de cada grupo, de cada comunidade, bem como valorize o conhecimento adquirido por meio de experiências cotidianas, em particular com relação à matemática, princípios tratados pelo autor como etnomatemática.

Assumindo a visão de que em cada meio social existe um conhecimento baseado nas experiências cotidianas e que esse conhecimento pode ser explorado e associado aos conceitos formais do ensino, buscou-se resgatar e conhecer a matemática praticada nas comunidades indígenas, seus mecanismos de mediação e metodologias específicas, em conformidade com a troca de conhecimento entre cursistas e formadores.

Durante o primeiro contato, o diagnóstico sobre noções numéricas foi necessário, durante o qual foi constatado que aqueles professores indígenas, semelhantemente aos indígenas localizados no Rio de Janeiro em 1556, descritos em documentos históricos como o Relato de Nicolas Barré (1957), possuíam processos próprios de contagem baseados na oralidade e na gesticulação. No entanto, adotam os algarismos numéricos do sistema HinduArábico, inclusive o difundem em suas aldeias.

Para compreendermos a estrutura do processo de contagem do povo Kaxinawá, tomemos como exemplo os numerais cinco e dez, expressos oralmente por esse povo por Meke Besti e Meke Rabe cujos significados são, respectivamente, uma mão e duas mãos. Notamos que os numerais 1 e 2 associados a outros elementos servem de base para expressar demais quantias. A construção de algumas dessas expressões pode ser verificada na Tabela 3: 
DOI: https://doi.org/ 10.20396/zet.v26il.8650889

Tabela 3 - Sistema de contagem Huni Kuĩ

\begin{tabular}{c|c|c}
\hline Sistema Decimal & Leitura Indígena & Estrutura de Composição \\
\hline 01 & Besti & 1 \\
\hline 02 & Rabe & 2 \\
\hline 03 & Rabe Besti & $2+1$ \\
\hline 04 & Rabe Rabe & $2+2$ \\
\hline 05 & Meke Besti & Uma mão \\
\hline 10 & Meke Rabe & Duas mãos \\
\hline 15 & Meke Rabe Inu Meke Besti & Duas mãos + uma mão \\
\hline 20 & Meke Rabe Yabi Tae Rabe & Duas mãos + dois pés \\
\hline
\end{tabular}

Fonte: Dados da pesquisa, 2014

Segundo defende Laplantine (2012), a linguagem consiste no modo pelo qual indivíduos de uma comunidade se comunicam, bem como o modo pelo qual interpretam o próprio saber e fazer-saber. Dessa forma, o uso de algarismo pode se apresentar necessário ou não em uma comunidade. Assim, pode-se entender o processo falado de contagem o mais natural e eficiente no interior de comunidades, indígenas ou não.

Ifrah (2005) ressalta que a invenção dos números deu-se devido a preocupações de ordem prática que atendesse anseios de comunidades que exigiam do homem a capacidade de realizar associações entre objetos ou animais, artifício conhecido como correspondência um a um, possibilitando a comparação sem recorrer à contagem abstrata e, dessa forma, o homem pôde praticar a aritmética antes de conhecer o número.

Da fusão da oralidade com a gesticulação estabeleceu-se o processo de contagem do povo Kaxinawá. No entanto, foram identificadas limitações durante a sondagem quanto ao reconhecimento e uso de algarismos, em especial para se representar quantidades superiores à classe das centenas.

Após o contato inicial, fez-se necessária a sistematização das ações e o estabelecimento de estratégias a serem desenvolvidas com a turma. As estratégias de trabalho nortearam-se segundo os princípios da etnomatemática, destacando-se três posturas adotadas: a construção de mapas mentais das aldeias; a contextualização da matemática; e ainda, de modo interligado à postura anterior, a elaboração de problemáticas pelos próprios profissionais em formação.

Sobre a construção dos mapas mentais, a atividade consistiu na construção individual de verdadeiros mapas das comunidades dos cursistas, objetivando o resgate de memória desses professores quanto às práticas e afazeres cotidianos no interior das aldeias que, posteriormente, foram associados aos conteúdos matemáticos. Tal ferramenta mostrou-se extremamente relevante no estabelecimento da relação intercultural, considerando que não houve contato direto com as comunidades e, portanto, foi necessária à compreensão da realidade do grupo. Um dos mapas pode ser verificado na Figura 1: 


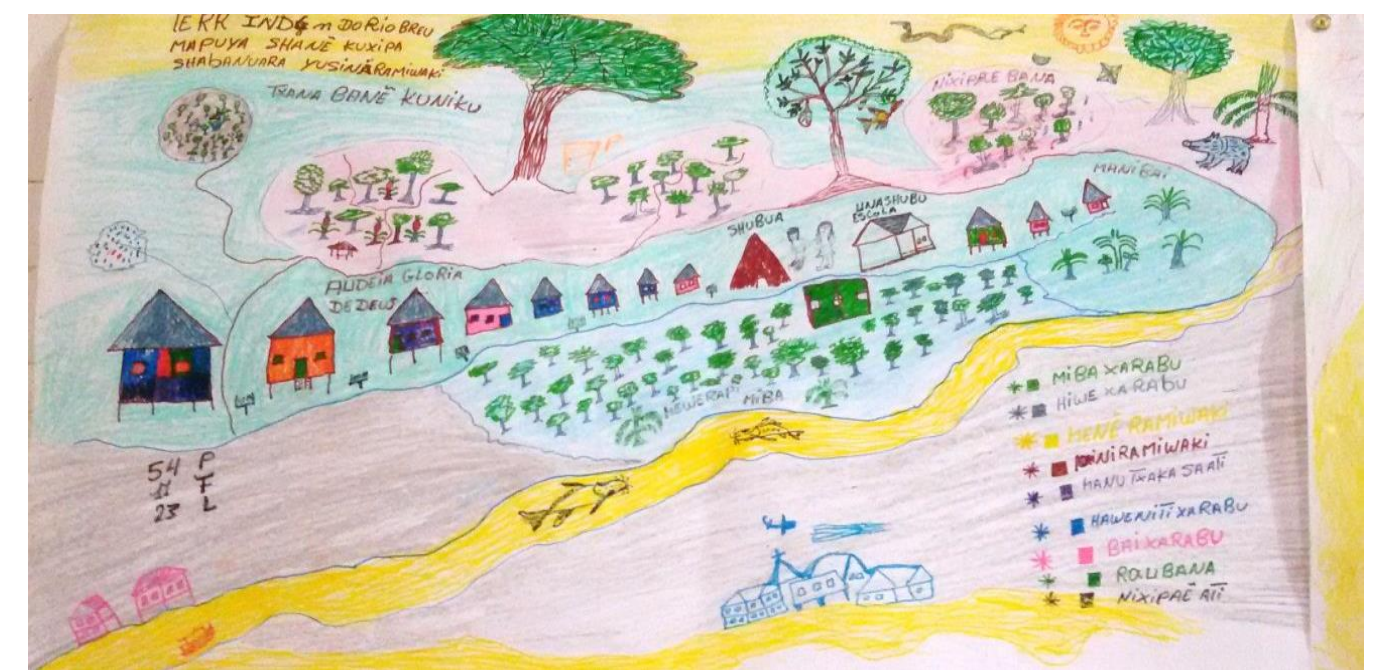

Figura 1 - Mapa Mental da Terra Indígena do Rio Breu construído por um professor cursista indígena Fonte: Dados da pesquisa, 2014

A Figura 1, chama atenção pela riqueza de detalhes, nota-se a presença dos dois espaços escolares: um deles denominado Una Shubu, que em português significa Escola Diversificada e o outro denominado Shubuã, a Escola Tradicional ou, ainda, Escola de Raiz.

A presença de duas unidades de ensino distintas se justifica quanto à natureza da mediação de conhecimentos, dado que em um dos espaços são socializados conhecimentos indígenas e não-indígenas, segundo os moldes do ensino sistematizado da cultura do "homem branco", enquanto que o outro é utilizado como espaço de afirmação de identidade cultural, sendo destinado ao compartilhamento de conhecimentos e costumes específicos do povo daquela comunidade indígena.

Após construídos os Mapas Mentais, cada cursista apresentou suas comunidades, destacando, dentre outros aspectos, as construções, as plantações, o criadouro de animais, os ambientes destinados aos rituais, as escolas tradicional e diferenciada presentes em muitas comunidades, os locais sagrados, os postos de saúde, os lagos e os presentes divinos naturais, tendo essas informações estruturado as ações docentes de acordo com as necessidades do grupo.

No tocante à contextualização dos conteúdos, buscou-se respaldo nos princípios delineados por D’Ambrósio (2013), o qual enfatiza que: “A matemática contextualizada se mostra como mais um recurso para solucionar problemas novos que, tendo se originado da outra cultura, chegam exigindo os instrumentos intelectuais da outra cultura”.

Seguindo essa vertente, no intuito de propor atividades matemáticas contextualizadas que valorizem e englobem práticas cotidianas indígenas e instrumentos educativos que reajam a aculturação, compara-se a função do professor não indígena, que atende um público indígena, à função do antropólogo, inclusive Laplantine (2012) propõe que uma das vocações do antropólogo hoje é desenvolver instrumentos que reajam à violência negadora das particularidades econômicas, sociais e culturais de um povo. 
Quanto à problematização matemática de situações cotidianas indígenas, foi fundamental a participação dos próprios professores indígenas. Sem a visão do ser integrante da comunidade, não teria sido possível a construção deste trabalho.

No processo ensinar/aprender, buscando-se elevar o nível de conhecimento, a qualidade de ensino e a relação dos conteúdos matemáticos propostos no cotidiano indígena, as problemáticas eram construídas após terem sido abordados os conteúdos básicos formais e tradicionais sobre educação matemática, como forma de sustentação para a resolução de tais dos problemas.

A seleção dos conteúdos deu-se com base no diagnóstico realizado durante o primeiro encontro, momento no qual foram estabelecidos temas centrais relacionados à Educação Matemática, e a partir da necessidade do público esses temas centrais foram delimitados e articulados com as aulas a cada encontro. Tais ações exigiam um planejamento contínuo e embasaram-se na flexibilização do currículo da educação escolar indígena.

Dentre as temáticas desenvolvidas, destaca-se que os conteúdos sobre as operações matemáticas fundamentais foram utilizados para balizar o curso, pois, nelas concentravam-se as maiores dificuldades diagnosticadas e relatadas pelos professores em formação.

A seguir, analisa-se algumas situações criadas pelos professores cursistas que foram discutidas e utilizadas como parte do processo de apresentação dos conteúdos, muitas foram propostas como atividades a serem desenvolvidas individualmente ou em grupo. As questões sofreram ajustes quanto à língua portuguesa tendo em vista que alguns indígenas não dominavam o idioma. No entanto, não houve descaracterização das propostas.

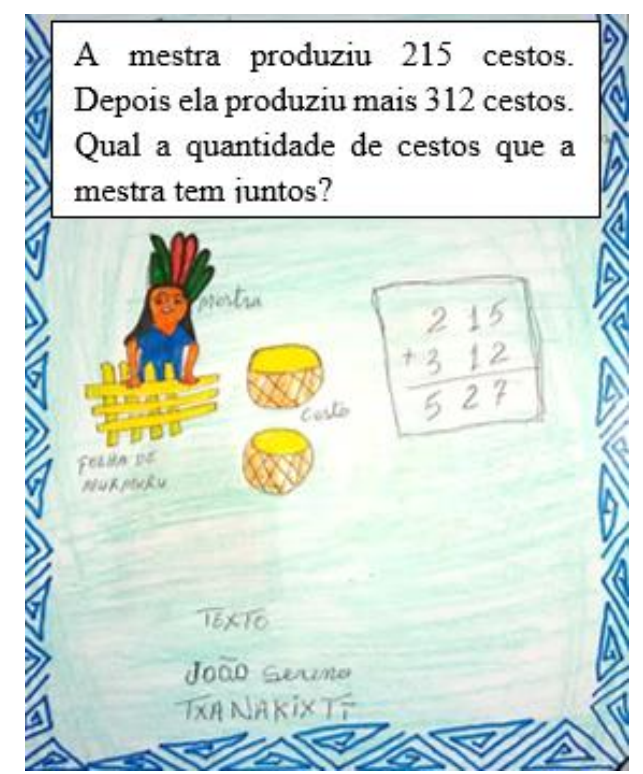

Figura 2 - Proposta aditiva baseada em afazeres artesanais indígenas

Fonte: Dados da pesquisa, 2014

Na proposta da Figura 2, inclusive fazendo uso de algoritmo, observa-se que são preservados os elementos e os afazeres da cultura indígena, tanto na contextualização, quanto 
na ilustração, enriquecendo a problemática e facilitando a compreensão dos demais cursistas através da aproximação dos conteúdos à realidade e à linguagem deles.

Destacamos que técnicas sobre as operações matemáticas fundamentais fizeram parte do desenvolvimento de todo o curso. Princípios multiplicativos também foram discutidos, porém a compreensão enfrentou obstáculos. Destacamos a língua portuguesa como um dos obstáculos pois, apesar da maioria dos cursistas falar português, há um vocabulário restrito, o que dificultou a comunicação.

Como estratégia, foram identificados professores que apresentaram facilidade na compreensão e no uso da operação, solicitando que eles realizassem a exposição do tema em sua língua materna. Essa estratégia obteve resultados positivos, que reforçam a importância do uso da língua de um povo no desenvolvimento de práticas educacionais.

Destacamos uma das atividades confeccionadas, Figura 03, durante o estudo sobre os processos multiplicativos.

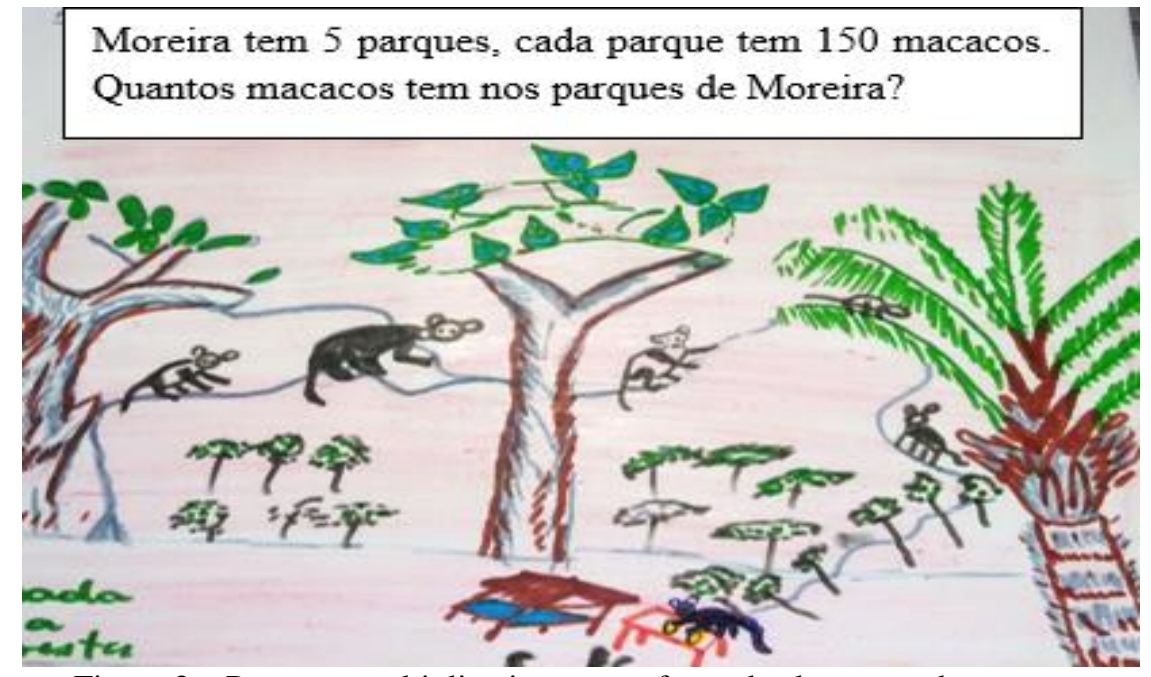

Figura 3 - Processo multiplicativo com reforço de elementos da natureza

Fonte: Dados da pesquisa, 2014

$\mathrm{Na}$ proposição da atividade à turma, diagnosticou-se que muitos solucionaram o problema por meio da adição, uma minoria acabou por adotar técnicas multiplicativas. Embora saiba-se que a matemática pode ser adaptada atendendo diferentes situações e que a compreensão de um problema pode se estabelecer de acordo com a interpretação do leitor, houve, portanto, a necessidade de reforçar o tema.

Assim, fazendo uso de elementos da natureza reforçaram-se as ideias multiplicativas, tomando como ferramenta gravetos de árvores que representavam as quantias a serem multiplicadas, situação que poderia ser reproduzida facilmente nas comunidades de cada profissional.

A técnica apresentada, consiste em cruzar os gravetos que representam quantidades e da interseção dos pontos pela sobreposição, obtemos o resultado da operação. Supondo que se queira multiplicar o número 5 pelo número 4, posiciona-se 5 gravetos num sentido, 
horizontal ou vertical, e outros 4 gravetos no sentido distinto, em seguida, conta-se os respectivos pontos de encontro para determinar o resultado da operação, conforme apresentado Figura 4.
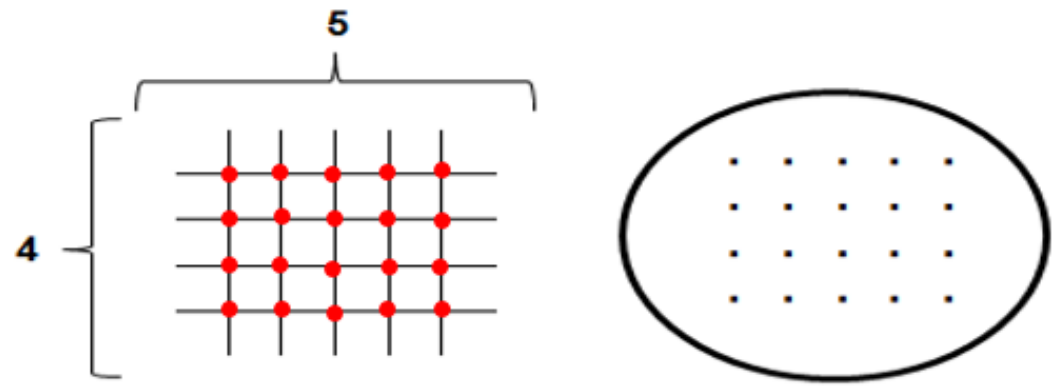

20

Figura 4 - Multiplicação com uso de recursos naturais

Fonte: Dados da pesquisa, 2014

Esse processo multiplicativo é bastante utilizado nos anos iniciais de ensino fundamental em escolas não indígenas de forma introdutória. Como adaptação da técnica utilizamos elementos inerentes à rotina dos professores como gravetos de árvores com rápida aceitação e assimilação.

Conhecida a realidade daqueles profissionais, verificou-se que muitos apresentavam domínio de técnicas agrícolas, inclusive, nas comunidades há um membro com formação em técnicas agroflorestais, os chamados Agentes Agroflorestais Indígenas, e, como em muitas aldeias o plantio de roças é realizado comunitariamente, esses conhecimentos acabam sendo compartilhados na prática. Era, então, esperado que problemas envolvendo técnicas agrícolas fossem propostos.

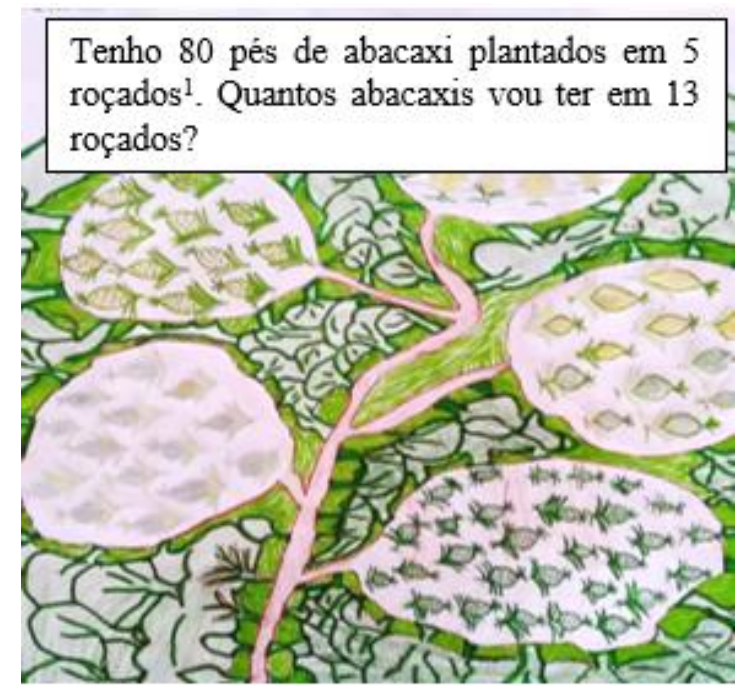

Figura 5 - Multiplicação em práticas agrícolas Fonte: Dados da pesquisa, 2014

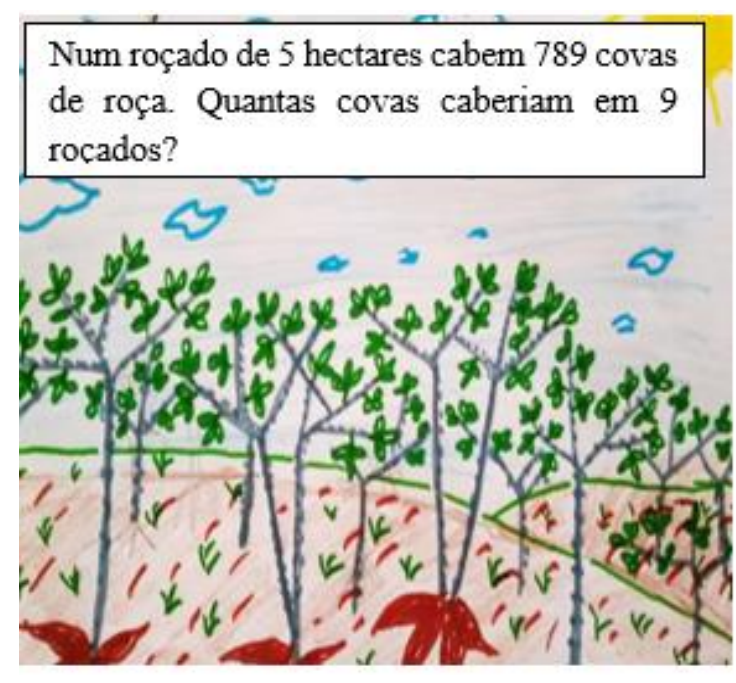

Figura 6 - Agricultura com uso da multiplicação Fonte: Dados da pesquisa, 2014

Destaca-se que muitos indígenas conhecem diferentes unidades de medida e as aplicam na delimitação de plantios ou mesmo na demarcação de suas terras, fato que 
demandou o estudo dos Sistemas de Medidas com consequente resgate histórico sobre os métodos utilizados por diferentes povos.

No caso dos povos indígenas, verificou-se que o hectare é uma unidade de medida de superfície muito difundida, inclusive, a atividade proposta na Figura 6, demonstra sua aplicabilidade. Contudo, identificou-se por meio da troca de experiências que muitas medições utilizadas se baseavam em aproximações, já que algumas delimitações se davam por meio de passos. Mediante a imprecisão de alguns mecanismos, apesar de extremamente importantes e úteis, frisou-se a importância da padronização.

Nessa perspectiva, Rozenberg (2006) justifica a padronização à expansão das relações internacionais entre os povos, ocorridas a partir do século $\mathrm{XX}$, mostrando ser indispensável um sistema de unidades bem definidas que pudesse ser utilizado internacionalmente em substituição às medidas imprecisas.

Assim, no processo formativo realizou-se uma abordagem questionadora quanto à necessidade de realização de medições em práticas cotidianas, constatando que muitas comunidades vivem como colonos ${ }^{4}$, com área de terra demarcadas, cultivadas e exploradas, segundo o interesse de seus moradores, sobrevivendo também da comercialização de suas produções.

Devido à manifestação de relações comerciais entre índios e não índios e sendo diagnosticado que muitos cursistas apresentavam dívidas, inclusive, com instituições financeiras, surgiu a preocupação em desenvolver conteúdos relativos à educação financeira. Tal área vem ganhando destaque nos dias atuais. Lucci, Zerrenner, Verrone \& Santos (2006) afirmam que a importância da educação financeira pode ser vista sob diversas perspectivas, uma delas seria a de bem-estar pessoal, outra a de bem-estar da sociedade, ambas podem culminar no comprometimento do futuro.

Sabendo que as relações comerciais dos povos indígenas assumem grandes proporções, a educação financeira desses povos surge como um tema relevante, inclusive, em 2013, a Associação das Produtoras de Artesanato das Mulheres Indígenas Kaxinawá de Tarauacá e Jordão, realizou uma exposição em Nova Iorque (EUA) com amostra de peças típicas da cultura indígena, tais situações geram receitas administradas pela própria comunidade.

Diante de situações aparentemente simples levantadas em sala, considerando o nível de ensino e o cenário apresentado, foram abordadas situações envolvendo conceitos matemáticos sobre matemática financeira, de modo dialogado, incentivando a participação através da exposição de experiências discutidas em conjunto, bem como a produção de atividades que envolvessem a temática, emergindo alguns problemas como o exposto na Figura 7.

\footnotetext{
${ }^{4}$ Aquele que cultiva um lote de terra.
} 


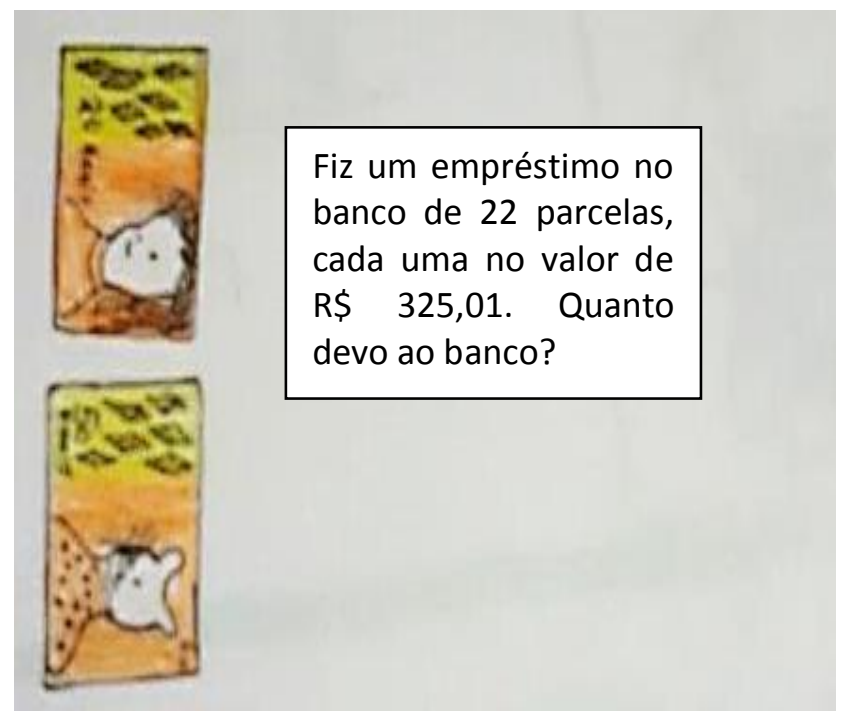

Figura 7 - Problema financeiro construído a partir da vivência de um professor indígena Fonte: Dados da pesquisa, 2014

Cohn (2001), nesse contexto, evidencia o domínio da matemática em sua forma acadêmica pelos povos indígenas como passo fundamental no estabelecimento de relações igualitárias entre índios e não índios no país, afirmando ainda que para haver tal domínio não seria necessário o abandono da matemática própria de comunidades indígenas.

Acredita-se que a proposição dada aos professores indígenas em elaborar problemas matemáticos que englobassem práticas culturais de seu próprio povo e ainda abordassem estas questões com a turma, vai ao encontro dos pressupostos defendidos por Alves (2010), o qual enfatiza que a escola deve se munir do conhecimento matemático de grupos sociais como proposta de ensino, de modo a promover o interesse ao aluno. Com efeito, o percurso formativo nos proporcionou compreender que:

Obcecados, na verdade, em uma única cultura, somos não apenas cegos à cultura dos outros, mas míopes quando se trata da nossa. A experiência da alteridade (e o desenvolvimento desta experiência) compromete-nos para ver o que nós não poderíamos sequer ter imaginado, tão nossa atenção está lutando para fixar-se sobre o que é habitual, familiar, quotidiano, e porque nós acreditamos que isso é óbvio, (Laplantine, 1987, p. 21, apud IbarrA, 2014, p.13). Tradução nossa.

Nesse sentido, durante o curso, buscou-se resgatar as vivências dos alunos com base nos princípios étnicos, associando a matemática não acadêmica praticada em comunidades indígenas à matemática tradicional, no intuito de desenvolver um trabalho sistematizado que valorizasse a cultura de um povo, bem como suprisse os anseios dessas comunidades. 


\section{Considerações Finais}

As instituições escolares em terras indígenas no Brasil firmaram-se ao longo dos 500 anos da nação e, apesar dos objetivos e justificativas que deram origem ao estabelecimento desses espaços terem sido extremamente aculturadores, os ambientes evoluíram, permitindo a concretização de unidades educacionais que visam a inclusão social, o respeito e a manutenção de conhecimentos ancestrais e o uso de métodos próprios de ensino.

A conquista pelos povos indígenas de uma escola diferenciada, bilíngue e intercultural, abre a discussão quanto à flexibilização do currículo, no sentido do diálogo entre os saberes acadêmicos, sistematizados, herdados da cultura ocidental e os legitimados cientificamente. Dessa forma, os saberes empíricos da cultura de um povo, sem submissão a comprovações ou validações científicas, é um conhecimento que não se pode negar.

Não se pode esquecer da responsabilidade social atribuída a figura do professor, agente direto do processo de educação escolar, cuja função não se restringe à transmissão de conhecimentos sistematizados. Hoje, esse profissional desempenha o papel de agente articulador, sendo formador de opiniões e elo nas relações externas.

Especificamente sobre o ensino de matemática, sabe-se que ao longo dos anos, ela constituiu como uma ciência que requer atenção, tanto no sentido de aprender, quanto de ensinar. Sua correlação com o cotidiano e sua questionada aplicação prática no contexto, indígena ou não, exige o domínio de definições teóricas e a compreensão de sua dimensão como ciência, especificidades que se acredita serem atendidas primordialmente por meio de uma boa formação profissional.

Desenvolver o conhecimento matemático, segundo o olhar do indígena, em face das problemáticas construídas pelos cursistas, possibilitou o enriquecimento e a aproximação dos conteúdos matemáticos acadêmicos à realidade desses povos, valorizando sua cultura e resgatando as práticas cotidianas.

Desse modo, fomentar percursos formativos com professores indígenas para atuar no seio de suas comunidades constitui, hoje, um dos principais desafios para os órgãos gestores na busca pela consolidação da Educação Escolar Indígena de qualidade, consequentemente, estão inseridos nesse processo de construção profissional, os professores de matemática e os que ensinam matemática em terras indígenas.

Apesar da relevância dos processos formativos e da existência de formações, a descontinuidade desses processos resulta em consequências extremamente danosas. Além disso, a estrutura das formações torna-se laboriosa para os professores indígenas, uma vez que esses profissionais desenvolvem o magistério paralelo à própria escolarização, gerando um professor que ensina na proporção que aprende, questiona da forma que é questionado e que, muitas vezes, compartilha dúvidas com seus alunos. 
Diante do exposto, entendemos que a educação escolar indígena hoje é uma realidade e pode ser considerada uma vitória para os povos indígenas, precisando ser vista pelos órgãos governamentais como uma prioridade. $\mathrm{O}$ desafio de fazer uma educação diferenciada existe, não apenas para os professores que ensinam matemática ou qualquer outra ciência, nem apenas para os órgãos governamentais, mas para todos que efetivamente participam do processo.

Para tanto, aponta-se a necessidade de consonância entre os sistemas educacionais municipal, estadual e federal, a fim de alcançarmos uma educação escolar indígena de qualidade e consolidada no país. Educação que, de fato, garanta o respeito entre os povos e valorize as culturas de comunidades locais e, com isso, possa haver interlocução durante o percurso formativo.

\section{Referências}

Acre (2013). Secretaria Estadual de Educação. Acre: A Educação Escolar Indígena em números. Coordenação de Educação Escolar indígena. Retirado em 11 de outubro, 2017, de: http://see.ac.gov.br/portal/index.php/institucional/ensino/indigena.

Acre (2014). Secretaria Estadual de Educação. Relatório do XI Curso de Formação de Professores em Magistério Indígena. Rio Branco: Coordenação de Educação Escolar indígena, Plácido de Castro.

Acre (2014). Secretaria Estadual de Educação. Demonstrativo das atividades pedagógicas em Cursos de Formação Intercultural, Diferenciada e Bilíngue de Professores Indígenas (período 2000-2010). Rio Branco: Coordenação de Educação Escolar Indígena.

Acre (2017). Secretaria Estadual de Planejamento. Acre em números: Rio Branco: Departamento de Estudos e Pesquisa - DEP. 10a ed. Retirado em 11 de outubro, 2017, de: $\quad$ http://www.ac.gov.br/wps/wcm/connect/4bb6ed00414180378291f31a15eb5101/acre-em-numeros2017.pdf?MOD=AJPERES\&CONVERT_TO=url\&CACHEID=4bb6ed00414180378291 f31a15eb5101.

Alves, E. R. (2010). Etnomatemática multiculturalismo em sala de aula: a atividade profissional como prática educativa. São Paulo: Porto de Idéias.

Barré, N. (1957) A carta de Nicolas Barré: "Tudo me leva a crer que esses nativos são o povo mais bárbaro e estranho que existe sobre a Terra". Revista Trópico. Dossiê Sonho Tropical. Retirado em 16 de março, 2015, de: http://www.revistatropico.com.br/tropico/html/textos/1540,1.shl.

Brasil (1988). Constituição da República Federativa do Brasil. Promulgada em 5 de outubro de 1988. Brasília, DF: Senado Federal.

Brasil (1998). Ministério da Educação. Referencial Curricular Nacional para a Educação Escolar Indígena. Brasília: MEC.

Brasil (2007). Ministério da Educação. Secretaria de Educação Básica. Secretaria de Educação Continuada, Alfabetização, Diversidade e Inclusão. Cadernos SECAD 3: Educação Escolar Indígena: diversidade sociocultural indígena ressignificando a escola. Brasília-DF. Retirado em 18 de novembro, 2014, de: http://portal.mec.gov.br/secad/arquivos/pdf/educacaoindigena. 
DOI: https://doi.org/ 10.20396/zet.v26il.8650889

Brasil (2012). Ministério da Educação. Diretrizes Curriculares Nacionais para a Educação Escolar Indígena. Brasília: MEC.

Brasil (2013). Ministério da Educação. Lei de Diretrizes e Bases da Educação Nacional LDB. 5a ed. Brasília: MEC.

Brasil (1845). Decreto Presidencial $\mathrm{N}^{\circ}$ 426, de 24 de julho de 1845, dispõe sobre a regulamentação de missões de catequize e civilização de índios. Rio de Janeiro. Retirado em 16 de outubro, 2014, de: http://legis.senado.leg.br/legislacao/ListaTextoSigen.action?norma=387574\&id=14390167\&idBinario=1 5771126\&mime=application/rtf.

Brasil (2009). Decreto Presidencial № 6.861, de 27 de maio de 2009, dispõe sobre a Educação Escolar Indígena, define sua organização em territórios etnoeducacionais, $e$ dá outras providências. Brasília DF: DOU de 28 de maio de 2009, seção 1, p.23.

Cohn, C. (2001) Escolas Indígenas no Maranhão um estudo sobre a experiência dos professores indígenas. In A. L. da Silva \& M. K. L. Ferreira (Orgs.), Práticas pedagógicas na escola indígena(pp. 107-122). São Paulo: Global.

Colares, A. A. (2013). Afirmação étnica e educação escolar indígena do povo Munduruku de Marituba (Belterra-Pará). Revista HISTEDBR, (50), 99-122, Disponível em: http://www.gepec.ufscar.br/publicacoes/educacao-no-campo/afrimacao-etnica-eeducacao-escolar-indigena-do.pdf/view.

Cunha, M. E. C. (2009). O Acre e a Educação Escolar Indígena, Intercultural, Diferenciada e Bilingue. Dissertação de Mestrado em Letras: Linguagem e Identidade. Rio Branco: Universidade Federal do Acre. Disponível em: http://livros01.livrosgratis.com.br/cp136122.pdf.

D’Ambrósio, U. (2011). Uma história concisa da matemática no Brasil. 2a ed. Petrópolis: Vozes.

D’Ambrósio, U. (2013). Etnomatemática: Elo entre as tradições e a modernidade. 5a ed. Belo Horizonte - MG: Autêntica Editora.

Gomes, M. P. (2013). Antropologia: ciência do homem: filosofia da cultura. 2a ed. São Paulo: Contexto.

Ibarra, G. M. (2014). L'enseignement et l'apprentissage de la représentation: une étude decas en maternelle: le "Jeu des Trésors". Education. Université de Bretagne OccidentaleBrest: Français.

Ifrah, G. (2005). Os Números: História de uma grande invenção. 11a ed. Rio de Janeiro: Editora Globo.

Laplantine, F. (2012). Aprender antropologia. São Paulo: Brasiliense.

Lévi-Strauss, C. (2012). A antropologia diante dos problemas do mundo moderno; apresentação Maurice Olender. São Paulo: Companhia das Letras.

Lucci, C. R., Zerrenner, S. A., Verrone, M. A. G., \& Santos, S. C. (2006). A influência da educação financeira nas decisões de consumo e investimento dos indivíduos. Disponível

em: http://www.ead.fea.usp.br/semead/12semead/resultado/trabalhosPDF/341.pdf.

Organização das Nações Unidas (1945). Carta das Nações Unidas, São Francisco, 26 de junho de 1945. Retirado em 23 de outubro, 2014, de: http://nacoesunidas.org/carta/.

Rêgo, P. A., \& Pereira, M. R. S. (2010). Educação indígena no Acre: uma experiência diferenciada. Retirado em 12 de novembro, 2014, de: http://www.ufac.br/portal/unidades-administrativas/orgaos- 
DOI: https://doi.org/ 10.20396/zet.v26il.8650889

complementares/edufac/revistas-eletronicas/revista-ramal-de-ideias/edicoes/edicao1/caminhos-da-educacao/educacao-indigena-no-acre.

Rozenberg, I. M. (2006). O Sistema Internacional de Unidades - SI. 3.a ed. São Paulo: Instituto Mauá de Tecnologia.

Recebido em: 31/10/2017

Aprovado para publicação em: 03/04/2018 